\title{
RANCANG BANGUN SISTEM INFORMASI PELAYANAN TAMU PADA HOTEL RENSA JAKARTA
}

\author{
1) Nuzuliarini Nuris, ${ }^{2)}$ Eka Rini Yulia \\ 1) Manajemen Informatika, AMIK BSI Jakarta \\ nuzuliarini.nzn@bsi.ac.id \\ 2) Sistem Informasi, STMIK Nusa Mandiri Jakarta \\ ekariniyulia@gmail.com
}

\begin{abstract}
Hotel Rensa in the recording of service users still use conventional information system that is the recording on a book, then recaptured to create a report of service data and payment transactions. The existing system has many shortcomings such as makes some errors, takes a long time in the search process data, as well as in the process of making reports. This research is expected to produce a service information system that is more quickly, effective, expendisious and efficient at Hotel Rensa. In order to support this research, the method of data calculation is done by observation, interview, literature study. The result of this research is data defender, data result, and transaction data report, can minimize error optimize the and data security.
\end{abstract}

\section{Keywords: Information System, Hotel Rensa Service.}

Abstrak - Hotel Rensa dalam pencatatan pengguna pelayanan masih menggunakan aplikasi secara konvensional yaitu pencatatan pada sebuah buku, kemudian direkap kembali untuk membuat laporan data pelayanan dan transaksi pembayaran. Sistem yang ada tersebut mempunyai banyak kekurangan diantaranya memungkinkan adanya kesalahan, membutuhkan waktu yang lama dalam proses pencarian data, maupun dalam proses pembuatan laporan. Dalam penelitian ini bertujuan untuk menghasilkan sebuah sistem informasi pelayanan kamar yang lebih cepat, tepat guna, efektif dan efisien pada Hotel Rensa. Guna menunjang penelitian ini, metode pengumpulan data dilakukan dengan cara observasi, wawancara, studi kepustakaan. Hasil dari penelitian ini adalah mempermudah karyawan Hotel Rensa dalam proses pelayanan, membantu dalam proses penginputan data, pencarian data, dan laporan data transaksi, dapat meminimalisasi adanya kesalahan dan mengoptimalkan keamanan data.

\section{Kata Kunci: Sistem Informasi, Pelayanan Hotel Rensa.}

\section{A. PENDAHULUAN}

Saat ini bisnis perhotelan berkembang begitu pesat. Hal ini disebabkan karena begitu banyaknya bermunculan hotel-hotel. Mulai dari hotel kecil sampai hotel berbintang. Dengan keadaan yang seperti itu, maka persaingan di dunia Perhotelan semakin ketat. Dalam hal ini, suatu hotel harus mempunyai keistimewaan agar lebih unggul dibanding hotel yang lain. Disini Sistem Informasi berperan sangat penting. Sebab bila hotel tersebut mempunyai Sistem Informasi yang baik, maka pelayanan hotel tersebut juga akan berjalan dengan baik juga. Hotel Rensa adalah hotel dengan peringkat bintang satu, namun Hotel Rensa juga menyediakan fasilitas yang dapat membuat tamu merasa puas. Diantaranya fasilitas layanan kamar itu sendiri, fasilitas restoran dan fasilitas laundry. Hotel Rensa juga menyediakan fasilitas ruang rapat.

Dalam mengolah informasi data tamu chek in maupun chek out, hingga laporan keuangan akhir, hotel tersebut masih menggunakan buku besar. Maka sering sekali data-data yang dilaporkan terjadi kesalahan. Maka seharusnya hotel tersebut mempunyai sistem informasi yang sudah terkomputerisasi. Hal tersebut juga akan mempermudah karyawan hotel dalam mengolah semua informasi data hotel, sehingga keakuratan data dapat terjamin. Dengan begitu karyawan hotel juga akan lebih mudah dalam mengolah informasi yang berhubungan dengan hotel tersebut.

Sistem informasi yang ada diharapkan dapat memberikan kemudahan dan kelancaran karyawan hotel dalam melayani tamu serta mengolah data yang berhubungan dengan pelayanan hotel.

\section{B. TINJAUAN PUSTAKA}

1. Sistem Informasi

a) Pengertian Sistem

Sekelompok elemen-elemen yang terintegrasi dengan tujuan yang sama untuk mencapai tujuan. Sistem juga merupakan suatu jaringan kerja dari prosedur-prosedur yang saling berhubungan, terkumpul bersama-sama untuk melakukan suatu kegiatan atau tujuan tertentu (Yakub, 2012). 
b) Pengertian Informasi

Informasi dapat dipahami sebagai pemrosesan input yang terorganisir, memiliki arti, dan berguna bagi orang yang menerimanya. Data berbeda dengan informasi. Data dapat didefinisikan sebagai fakta-fakta yang masih mentah atau acak yang menjadi input untuk proses yang menghasilkan informasi (Tantra, 2012).

c) Pengertian Sistem Informasi

Sistem informasi adalah cara yang terorganisir untuk mengumpulkan, memasukan, dan memproses data dan menyimpannya, mengelola, mengontrol dan melaporkannya sehingga dapat mendukung perusahaan atau organisasi untuk mencapai suatu tujuan. (Tantra, 2012).

Menurut Hall (2001) Sistem informasi adalah sebuah rangkaian prosedur formal dimana data dikelompokkan, diproses menjadi informasi, dan didistribusikan kepada pemakai. (Kadir A. , 2014).

\section{Entity Relationship Diagram}

Entity Relationship Diagram (ERD)
merupakan suatu model data yang dikembangkan berdasarkan objek. Entity Relationship Diagram (ERD) digunakan untuk menjelaskan hubungan antar data dalam basis data kepada pengguna secara logis (Sutabri, 2012).

ERD digunakan oleh perancang sistem untuk memodelkan data yang nantinya akan dikembangkan menjadi basis data (database). Model data ini juga akan membantu pada saaat melakukan analisis dan perancangan basis data, karena model data ini akan menunjukan bermacam-macam data yang dibutuhkan dan hubungan antar data. ERD ini juga merupakan model konseptual yang dapat mendeksripsikan hubungan antara file yang digunakan untuk memodelkan struktur data serta hubungan antar data. ERD terbagi menjadi tiga komponen, yaitu entitas (entity), atribut (attribute), dan relasi atau hubungan (relation). Secara garis besar entitas merupakan dasar yang terlibat dalam sistem. Atribut atau field berperan sebagai penjelas dari entitas, dan relasi atau hubungan menunjukkan hubungan yang terjadi antara dua entitas.

a) Entitas (Entity)

Entitas (Entity) menunjukkan obyek-obyek dasar yang terkait didalam sistem. Obyek dasar dapat berupa orang, benda atau hal lain yang keterangannya perlu disimpan dalam basis data. Untuk menggambarkan entitas dilakukan dengan mengikuti aturan-aturan sebagai berikut:
1) Entitas dinyatakan dengan simbol persegi panjang.

2) Nama entitas berupa kata benda tunggal.

3) Nama entitas sedapat mungkin menggunakan nama yang mudah dipahami dan menyatakan maknanya dengan jelas.

b) Atribut (Attribute)

Atribut sering juga disebut sebagai properti (property), merupakan kerterangan-keterangan yang terkait pada sebuah entitas yang perlu disimpan sebagai basis data (Yakub, 2008). Atribut berfungsi sebgai penjelas sebuah entitas untuk menggambarkan atribut yang dilakukan dengan mengikuti aturan sebagai berikut:

1) Atribut dinyatakan dengan simbol elipps.

2) Nama atribut dituliskan dalam simbol elipps.

3) Nama atribut berupa kata benda tunggal.

4) Nama entitas sedapat mungkin menggunakan nama yang mudah dipahami dan menyatakan maknanya dengan jelas.

5) Atribut dihubungkan dengan entitas yang bersesuaian dengan menggunakan garis.

c) Relasi (relations)

Relasi atau hubungan adalah kejadian atau transaksi yang terjadi di antara dua entitas yang keterangannya perlu disimpan dalam basis data (Yakub, 2008). Aturan penggambaran relasi antar entity adalah:

1) Relasi dinyatakan dengan simbol belah ketupat.

2) Nama relasi dituliskan dalam simbol belah ketupat.

3) Nama relasi menggunakan kata kerja aktif (diawali awalan me) tunggal.

4) Nama relasi sedapat mungkin menggunakan nama yang mudah dipahami dan dapat menyatakan maknanya dengan jelas.

d) Derajat relationship (kardinalitas)

Model relasi ini berdasarkan persepsi dunia nyata di antaranya himpunan objek dasar dan relasi antar entitas. Entitas dapa diartikan sebgai objek dan didefinisikan secara unik, dan objeknya dapat berbentuk orang, barang, dan sebagainya. Kardinalitas relasi menunjukkan maksimum entitas yang dapat berelasi dengan entitas pada himpunan entitas yng lain. Kardinalitas relasi yang terjadi di antara 2 himpunan 
entitas (misalkan A dan B) dapat berupa satu ke satu (one to one), satu ke banyak (one to many), banyak ke satu (many to one) dan banyak ke banyak (many to many).

1) Satu ke Satu (One to One)

Berarti setiap entitas pada himpunan entitas $A$ berhubungan dengan paling banyak dengan satu entitas pada himpunan entitas $B$, dan begitu juga sebaliknya setiap entitas pada himpunan entitas $B$ berhubungan dengan paling banyak dengan satu entitas himpunan entitas B.

2) Satu ke banyak (One to Many)

Berarti setiap entitas pada himpunan entitas $A$ dan dapat berhubungan dengan banyak entitas pada himpunan entitas B, tetapi tidak sebaliknya, di mana setiap entitas pada himpunan entitas berhubungan dengan paling banyak dengan satu entitas pada himpunan entitas $A$.

3) Banyak ke Satu ( Many to One)

Berarti setiap entitas pada himpunan entitas $A$ berhubungan dengan paling banyak dengan satu entitas pada himpunan $B$, tetapi tidak sebaliknya, di mana setiap entitas pada himpunan entitas $A$ berhubungan dengan paling banyak satu entitas pada himpunan entitas B.

4) Banyak ke Banyak (Many to Many) Berarti setiap entitas pada himpunan entitas $A$ dapat berhubungan dengan banyak entitas pada himpunan entitas $B$, demikian juga sebaliknya, di mana setiap entitas pada himpunan entitas $B$ dapat berhubungan dengan banyak entitas pada himpunan entitas $A$.

\section{Logical Record Stucture}

LRS (Logical Record Structure) aturan-aturan dalam melakukan transformasi E-R Diagram ke logical record structure sebagai berikut: (Ladjamudin, 2006)

a) Setiap entity akan diubah kebentuk sebuah kotak dengan nama entity berada diluar kotak dan atribut berada didalam kotak.

b) Sebuah relasi kadang disatukan dalam sebuah kotak bersama entity, kadang dipisah dalam sebuah kotak sendiri.

\section{METODE PENELITIAN}

1. Metode Pengembangan Perangkat Lunak

Metode yang digunakan adalah Model SDLC (Software Development Life Cycle) air terjun (Waterfall) sering juga di sebut model sekuensi linier (Sequential liniar) atau alur hidup klasik (classic life cycle). Model air terjun menyediakan pendekatan alur hidup perangkat lunak secara sekuensial atau terurut dimulai dari analisis, desain, pengkodean, pengujian, dan tahap pendukung (support). Berikut adalah gambar model air terjun (Rosa \& Shalahudin, 2013):

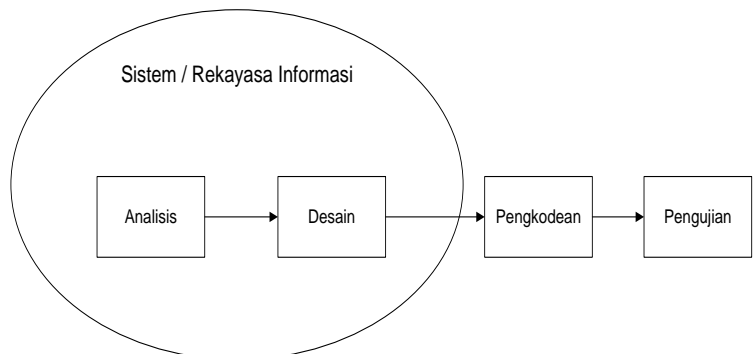

Sumber: (Rosa \& Shalahudin, 2013)

Gambar 1. Ilustrasi waterfall

a) Analisis kebutuhan

Pada Proses pengumpulan kebutuhan meliputi proses check-in, check-out, pemanfaatan layanan restoran, layanan laundry juga pembuatan laporan.

b) Desain

Merancang sistem dengan hubungan antar entitas yang ada dalam sistem dijabarkan dalam Data Flow Diagram dan juga Entity Relationship Diagram. Rancangan database dari sistem usulan, peneliti gambarkan dalam bentuk Logical Record Structure dan Struktur Tampilan program dengan tampilan sesederhana mungkin agar mudah digunakan pengguna.

c) Pembuatan Kode Program

Pembuatan kode program dengan memanfaatkan software borland delphi 7 . 


\section{Teknik Pengumpulan Data}

Teknik yang digunakan untuk mengumpulkan data yang diperlukan dalam penelitian ini adalah:

a) Observasi

Yaitu pengamatan secara langsung ke objek yang mau diteliti, dalam hal ini yaitu perusahaan yang sedang diadakan penelitian.

b) Wawancara

Yaitu teknik pengumpulan informasi dengan melakukan tanya jawab secara langsung dengan staf yang menangani masalah pelayanan tamu.

c) Studi Pustaka

Yaitu mengadakan penelitian ilmiah diperpustakaan dengan cara membaca buku-buku yang terkait dengan penelitian kita sebagai referensi.

\section{HASIL DAN PEMBAHASAN}

\section{Analisis Kebutuhan}

Analisa kebutuhan merupakan langkah awal untuk menentukan perangkat lunak seperti apa yang akan dihasilkan, ketika kita melaksanakan sebuah proyek pembuatan perangkat lunak. Perangkat lunak yang baik dan sesuai dengan kebutuhan pengguna sangat bergantung kepada keberhasilan dalam melakukan analisa kebutuhan. Tidak peduli bagaimana hebatnya seseorang dalam menulis kode perangkat lunak, atau membuat antar muka yang menawan, jika terjadi kesalahan dalam analisa kebutuhan, itu artinya perangkat lunak yang dibuat belum siap pakai.

\section{Analisis Kebutuhan Fungsional}
a) Admin mengelola data kamar
b) Admin mengelola data makanan dan minuman
c) Admin mengelola data pakaian

d) Admin mengelola data tamu

e) Admin dapat menginput registrasi tamu

f) Admin dapat menginput data layanan restoran dan laundry

g) Admin dapat mengkalkulasi pembayaran tamu yang akan check-out

h) Admin dapat membuat laporan transaksi

\section{Analisis Kebutuhan Sistem} a) Menyediakan halaman form untuk
mengelola data kamar

b) Menyediakan halaman form untuk mengelola data makanan dan minuman

c) Menyediakan halaman form untuk mengelola data pakaian

d) Menyediakan halaman form untuk mengelola data tamu

e) Menyediakan halaman form untuk menginput tamu yang menyewa kamar

f) Menyediakan halaman form untuk menginput data layanan restoran dan laundry

g) Menyediakan halaman form untuk mengkalkulasikan pembayaran tamu yang akan check-out

h) Menyediakan halaman form untuk membuat laporan transaksi

\section{Perancangan}

Perancangan adalah proses untuk mengaplikasikan berbagai macam teknik dan prinsip untuk tujuan pendefenisian secara rinci suatu perangkat, proses atau sistem agar dapat direalisasikan dalam suatu bentuk fisik. Tujuan Perancangan adalah menghasilkan suatu model atau penggambaran dari suatu entity yang akan dibangun kemudian.

Dari hasil analisa yang dilakukan terhadap sistem berjalan dan untuk sistem yang akan datang, berikut ini perancangan sistem pelayanan pada Hotel Rensa: 


\section{Entity Relationship Diagram}

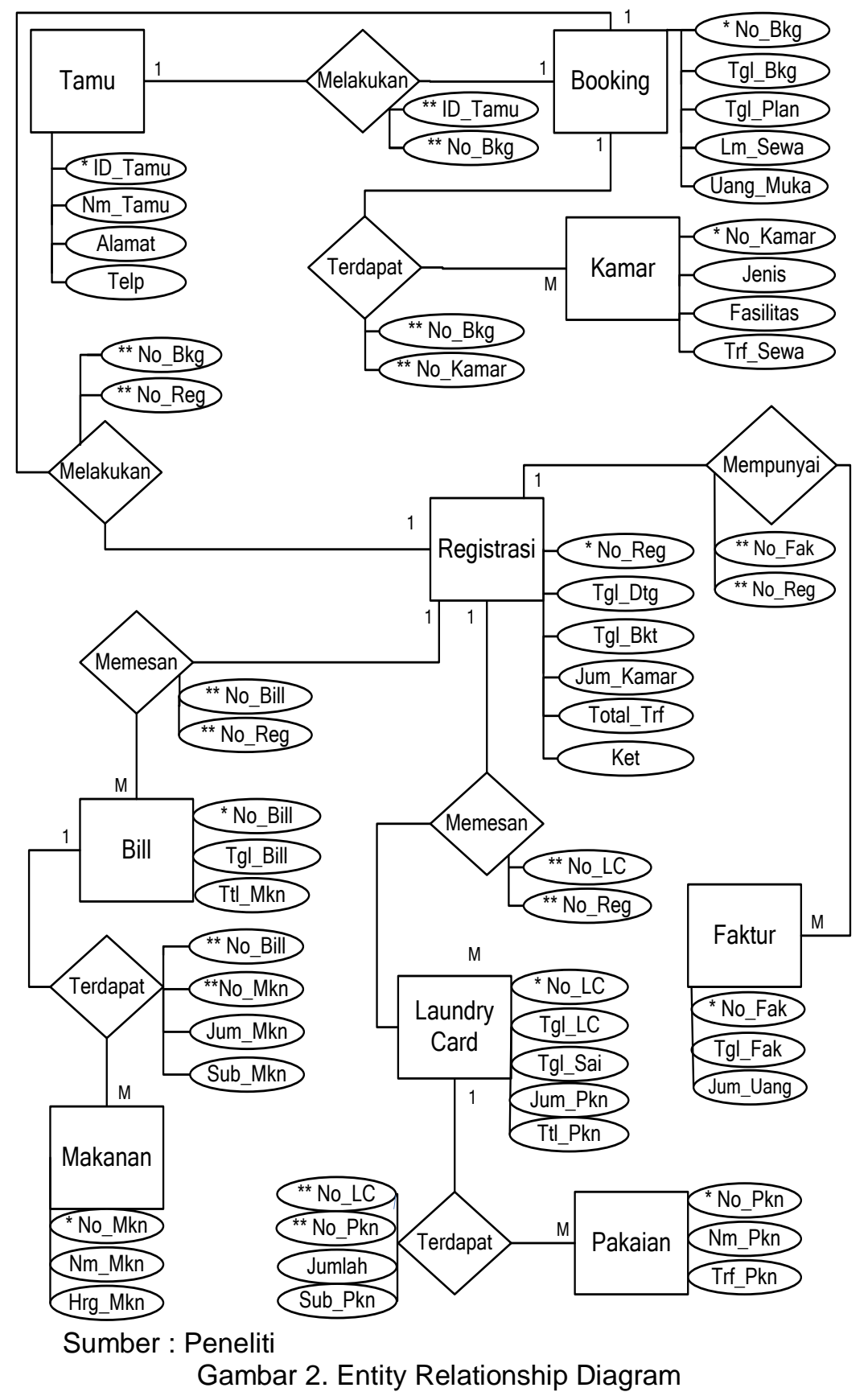




\section{Transform ERD ke LRS}

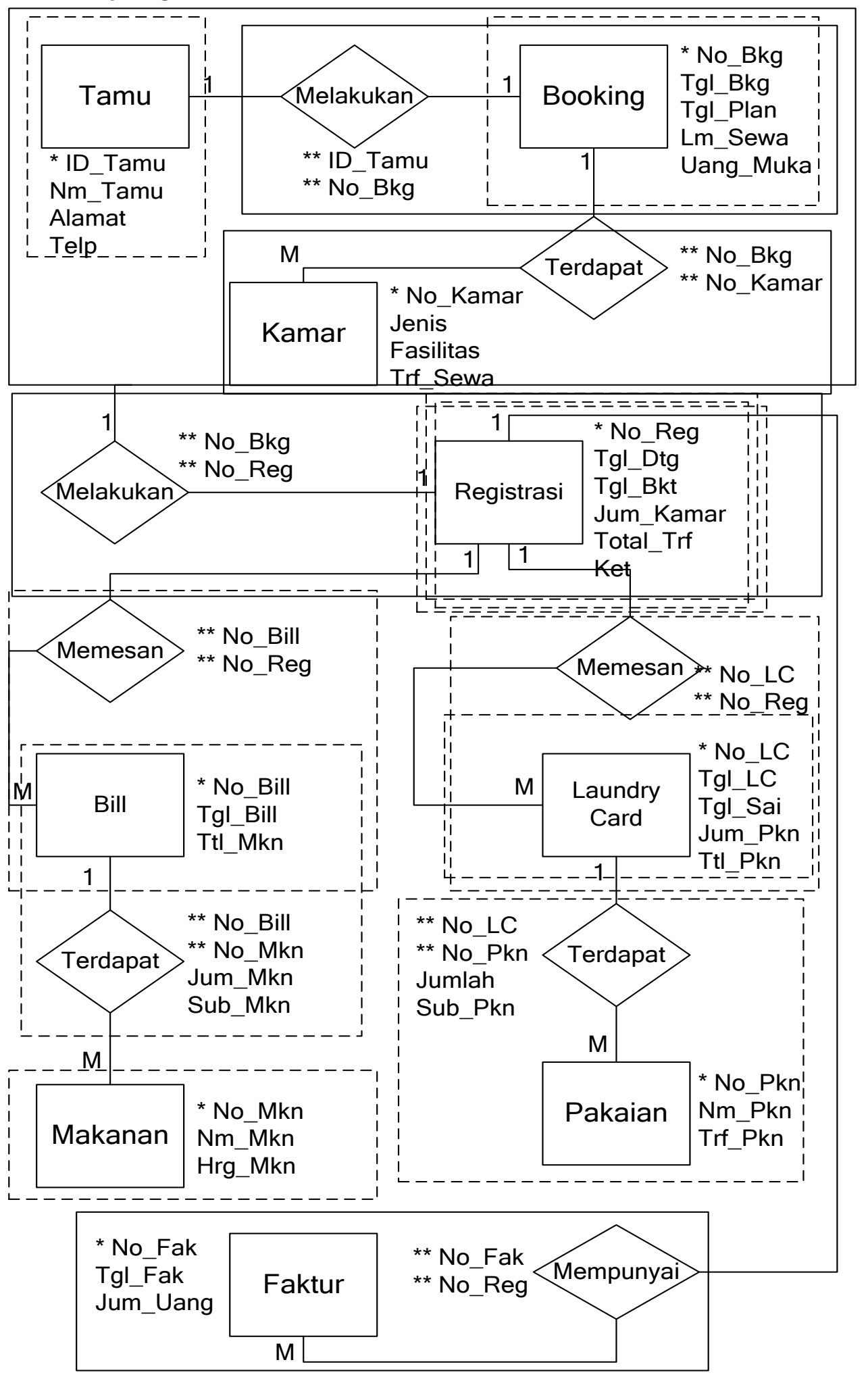

Sumber : Peneliti

Gambar 3. Transform ERD ke LRS 


\section{Logical Record Structure}

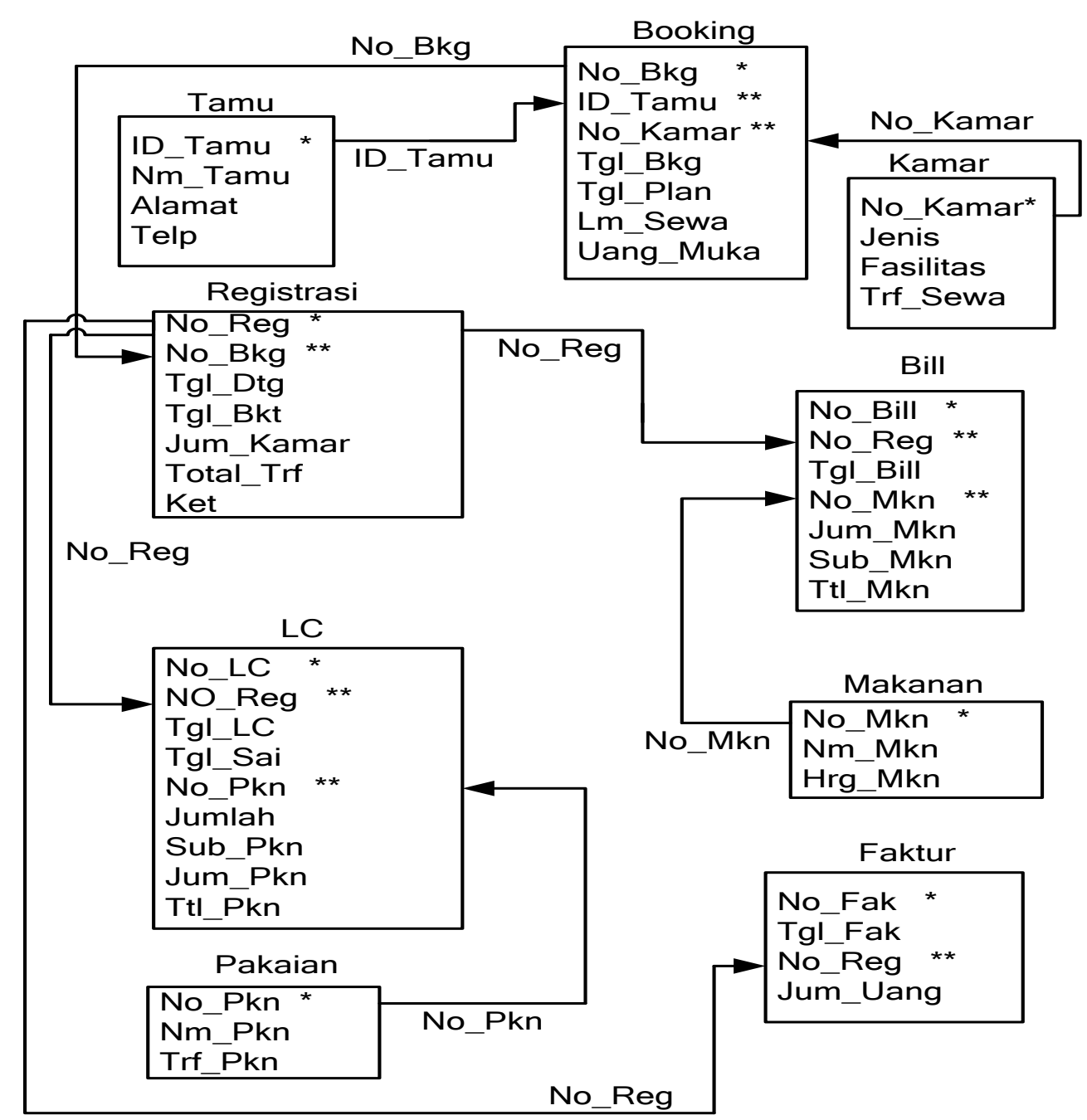

Sumber : Peneliti

Gambar 4. Logical Record Structure

\section{Spesifikasi File}

a) File Kamar

Nama File

Media

Isi

Organisasi

Primary Key

Panjang Record

Jumlah Record : $\left(1^{*} 12^{\star} 3\right)=36$ record

Tabel 1. Spesifikasi Basis Data Kamar

\begin{tabular}{|c|l|c|c|c|c|}
\hline No & Nama Field & Tipe & Lebar & Desimal & Keterangan \\
\hline 1 & No_Kamar & text & 3 & - & Primary key \\
\hline 2 & Jenis & text & 15 & - & \\
\hline 3 & Fasilitas & text & 30 & - & \\
\hline 4 & Hrg_Sewa & Currency & 8 & - & \\
\hline
\end{tabular}

Sumber : Peneliti b) File Tamu

Nama File : Tamu

Media : Hardisk

Isi : Data tentang Tamu

Organisasi : Index Sequential

Primary Key : No_Tamu

Panjang Record : 108 bytes

Jumlah Record : $\left(15^{\star} 30^{*} 12\right)^{\star} 3=$

16200 Record

Tabel 2. Spesifikasi Basis Data Kamar

\begin{tabular}{|c|l|c|c|c|c|}
\hline No & Nama Field & Tipe & Lebar & Desimal & Keterangan \\
\hline 1 & ID_Tamu & Text & 16 & - & Primary key \\
\hline 2 & Nm_Tamu & Text & 30 & - & \\
\hline 3 & Alamat & Text & 50 & - & \\
\hline 4 & Telp & Text & 12 & - & \\
\hline
\end{tabular}

Sumber : Peneliti 


\section{Rancangan Tampilan}

a) Struktur Tampilan

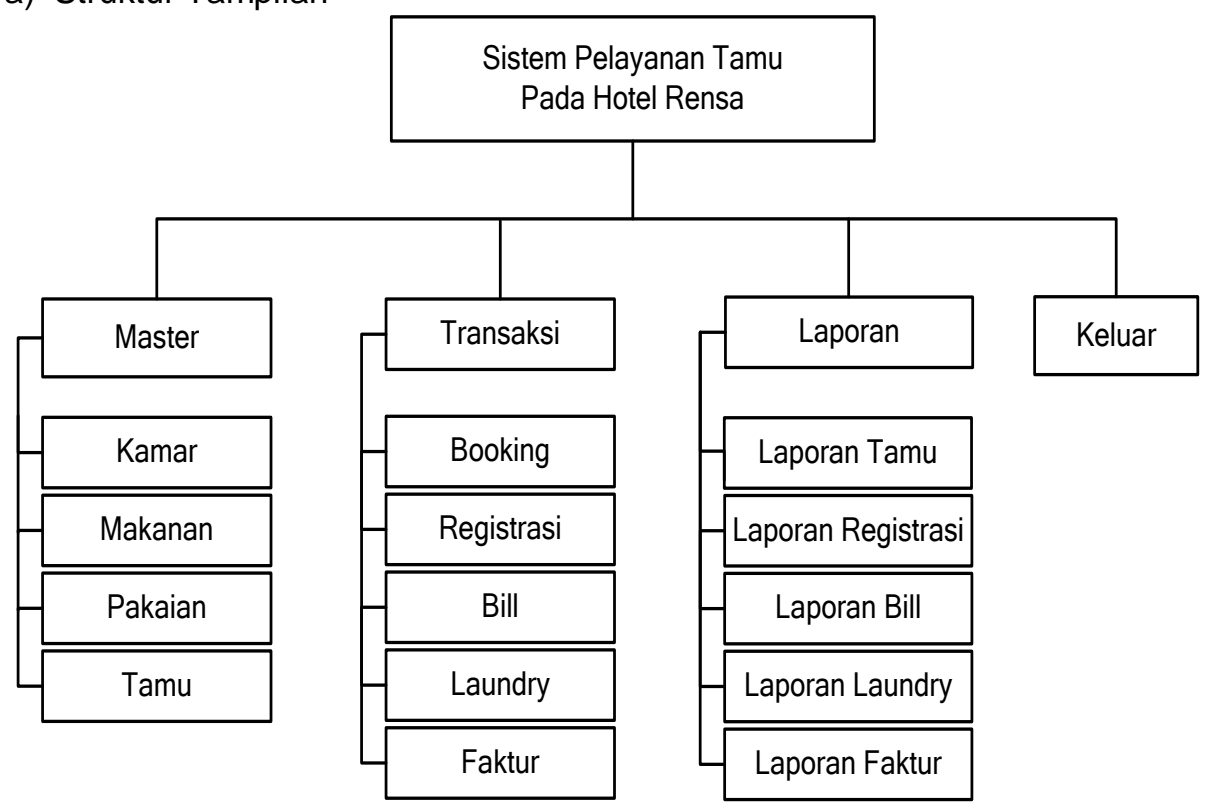

Sumber : Peneliti

Gambar 5. Struktur Tampilan Sistem Pelayanan Tamu Hotel Rensa

b) Tampilan Form Kamar

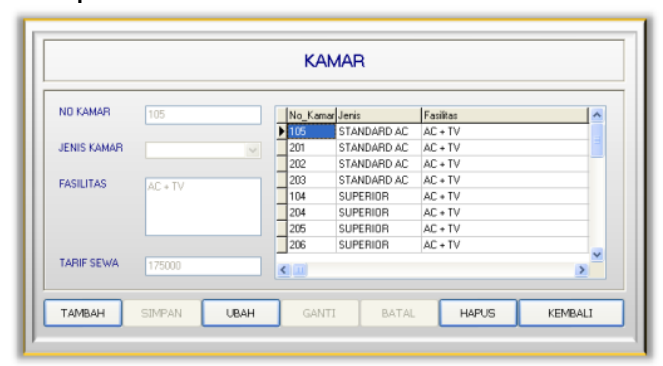

c) Tampilan Form Tamu

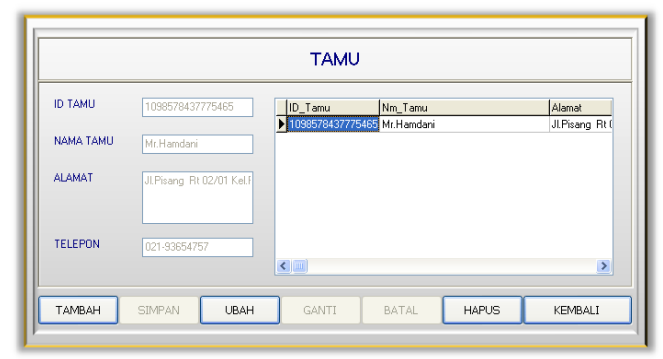

\section{E. KESIMPULAN}

Setelah melakukan analisa pada sistem pelayanan tamu pada Hotel Rensa, peneliti mengambil beberapa kesimpulan yang berkaitan dengan pengolahan data dan informasi pada sistem tersebut. Kesimpulan peneliti antara lain :

1. Adanya keamanan penyimpanan data selama dalam proses pengolahan data pelayanan tamu.

2. Dalam sistem berjalan semua hal mengenai data masih dilakukan secara manual, tempat penyimpanan datapun masih disimpan didalam sebuah buku yang mencakup semua data tentang pelayanan tamu.

3. Laporan yang dibuat masih kurang lengkap dan lambat karena keterbatasan pengolahan data yang dilakukan secara manual.

Untuk membantu sistem yang baru maka peneliti merancang sebuah sistem informasi berbasis komputer yaitu suatu aplikasi program pelayanan tamu untuk mendukung proses yang ada di Hotel Rensa dengan cepat dan aman.

\section{DAFTAR PUSTAKA}

[1] Kadir, A. (2014). Pengenalan Sistem Informasi Edisi Revisi. Yogyakarta: Andi.

[2] Ladjamudin, A. B. (2006). Rekayasa Perangkat Lunak. Yogyakarta: Graha IImu.

[3] Rosa, A., \& Shalahudin, M. (2013). Rekayasa Perangkat Lunak Terstruktur dan Berorientasi Objek. Bandung: Informatika.

[4] Sutabri, T. (2012). Analisis Sistem Informasi. Yogyakarta: Andi.

[5] Tantra, R. (2012). Manajemen Proyek Sistem Informasi. Yogyakarta: Andi.

[6] Yakub. (2008). Sistem Basis Data Tutorial Konseptual. Yogyakarta: Graha IImu.

[7] Yakub. (2012). Pengantar Sistem Informasi. Yogyakarta: Graha IImu. 